\title{
Comparative Evaluation of Antibacterial and Smear Layer Removal Efficacy of Two Different Herbal Irrigants: An In Vitro Study
}

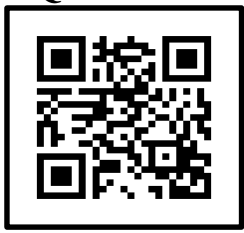

\section{ARVIND KUMAR'1, A SHEERIN SARTHAJ², S MARIA ANTONY33}

INTRODUCTION: Irrigation during root canal therapy is especially needed for teeth with complex internal anatomy. Biomechanical preparation of root canal produces "smear layer" which gets embedded with debris and microorganisms. The major side effects of these widely used chemical irrigants such as Sodium hypochlorite for antibacterial efficacy and EDTA for smear layer removal has led to the search of a more biocompatible irrigant.

MATERIALS AND METHODS: Azadirachta indica(neem) and Ocimum sanctum(tulsi) extract were used in this study as herbal irrigants to evaluate the above mentioned properties by the q PCR method and SEM analysis.

RESULTS: In antimicrobial efficacy, the Mean value of NaOcl showed higher antimicrobial efficacy followed by Neem leaf extract and the lower antimicrobial efficacy was recorded with Tulsi extract. Similarly, the mean smear layer removal by different irrigants at different root levels, EDTA showed the maximum smear layer removal, followed by Neem leaf extract and Tulsi extract showed the least smear layer removal. Hence Tulsi has poor smear layer removal efficacy and comparable antimicrobial efficacy when compared with Neem extract STATISTICAL ANALYSIS: The collected data were analyzed by one-way analysis of variance to compare the mean of the groups. The posthoc test (Tukey) was performed to find the interrelationship between different groups for significant difference $(\mathrm{P}<0.05$; confidence interval 95\%).

CONCLUSION: From this study, these two herbal irrigants are proved to be safe and effective. It can be concluded that neem leaf extract has a significant antimicrobial efficacy against E. faecalis and significant smear layer removal efficacy compared to $17 \%$ EDTA.

KEYWORDS: Antibacterial, Smear Layer, Herbal Irrigants, qPCR, Scanning Electron Microscopy

\section{INTRODUCTION}

Pulpal and peri-radicular infections are caused by a variety of microorganisms in the root canal. The aim of the root canal therapy is to eliminate microorganisms from the root canal to provide an appropriate environment for tissue healing. Success rate of endodontic treatment depends upon adequate biomechanical preparation, irrigation, and obturation of the root canal. ${ }^{2}$ Irrigation during root canal therapy is especially needed for teeth with complex internal anatomy. Even though Sodium hypochlorite is the most effective irrigating solution because of its dissolution property of the organic content, it also has several undesirable characteristics such as toxic and potential irritant to the periapical tissues and its unpleasant smell and taste. ${ }^{3}$

Biomechanical preparation of root canal produces "smear layer" which gets embedded with debris and microorganisms. The smear layer may interfere with the penetration of intracanal medicaments and sealers into the dentinal tubules. Ethylene-Diamine Tetra Acetic acid (EDTA) is effective for smear layer removal. The major drawback of EDTA is that it reacts with calcium ions in dentine, produces calcium chelation, it promotes dentine decalcification at depths of $20-30 \mu \mathrm{m}$ within 5 minutes. EDTA decreases the dentin microhardness and its increased with increased time of application. ${ }^{1,3}$

The major side effects of these widely used chemical irrigants such as Sodium hypochlorite and EDTA led to the search for a more biocompatible irrigant. Among the various herbs one such herbal alternative is Azadirachta indica (Neem). Not just one but all parts of medicinal herbs and plants can be used therapeutically. ${ }^{3}$ Another one is Ocimum sanctum (Tulsi), which is native to the Indian subcontinent, consisting mostly of Eugenol (70\%), Aerosol acid, Oleanolic acid, $\beta$ - element(11\%), $\beta$-caryophyllene and germacrene. The constituents of these widely used herbal irrigants are well known for antiinflammatory; immune-modulatory, antibacterial, antifungal, antiviral, antioxidant, and anti-carcinogenic properties. ${ }^{4}$ Hence these two herbal irrigants were chosen for this study.

Hence, the present study was undertaken to evaluate the efficiency of $17 \%$ EDTA, Neem leaf extract and Tulsi extract endodontic irrigants in 
smear layer removal through scanning electron microscopic image analysis and the Antimicrobial efficacy of herbal alternatives (Azadirachta indica extract, Ocimum sanctum) and to compare it with $3 \%$ sodium hypochlorite against $\mathrm{E}$. faecalis by qPCR.

\section{MATERIALS AND METHOD}

Preparation of Azadirachta indica and Ocimum sanctum extract

$100 \mathrm{~g}$ of neem and tulsi leaves were tied in a cloth and soaked in $800 \mathrm{ml}$ of distilled water. To make the solution attain a $25 \%$ concentration, the beaker was boiled under low flame. It was filtered using a filter paper. Herbal irrigants were subjected to phytochemical study for the presence of its appropriate active constituents.

\section{Grouping}

120 maxillary central incisors were categorized into two groups, and 6o samples were allocated for each group; Group 1: Antimicrobial efficacy $(n=60)$, Group 2: smear layer removal efficacy $(n=60)$.

Group I was divided into three sub-groups:

Group IA: $\mathrm{NaOCl}(\mathrm{n}=\mathbf{2 0})$

Group IB: Neem extract $(\mathrm{n}=\mathbf{2 0})$

Group IC: Tulsi extract $(\mathrm{n}=\mathbf{2 0})$

All the 120 teeth were decoronated at the level of CEJ to standardize the length of $12 \mathrm{~mm}$. E. Faecalis was inoculated into the root canal for about 21 days. In the E. Faecalis inoculated canal, Cleaning and shaping were done by using K-files(Mani, Kfiles) apically up to $30 \mathrm{~K}$-size and coronal up to 50 $\mathrm{K}$-size files inside the UV-Chamber. To prevent taper lock, the needle was kept passively at $1 \mathrm{~mm}$ from the working length. The specification of the needle was 25 gauge, followed by irrigation with 6 $\mathrm{ml}$ of the irrigants at a rate of approximately 2 $\mathrm{ml} / 15$ seconds. Drying of canals was ensured with paper points. Contact time was 20 minutes. Samples were obtained by using Headstoerm files(Mani H- files). Samples were analyzed by qPCR (Mastercycler x50) to obtain the threshold cycle $(\mathrm{CT})$ value of samples.

\section{Real-Time quantitative polymerase chain reaction \\ The universal primers used amplified enterococcal DNA sequence. The PCR evaluation was done as follows, initial denaturation at $94^{\circ} \mathrm{C}$ for 15 seconds,}

annealing at $55^{\circ} \mathrm{C}$ and extension at $72^{\circ} \mathrm{C}$ for 45 seconds and then cooled to $4^{\circ} \mathrm{C}$ until removed. The thermo cycler (790o HT Real-time PCR system).

In Group II, For analyzing smear layer removal efficacy, Samples were further divided into 3 subgroups

Group IIa: $\operatorname{EDTA}(\mathrm{n}=\mathbf{2 0})$, Group IIb: Neem extract $(\mathrm{n}=\mathbf{2 0})$, Group IIc: Tulsi extract $(\mathrm{n}=20)$.

After decoronation, Cleaning and shaping were done by using K-files (Mani K-files) 30 size apically and 6o sizes coronally, 25-G needle tip was placed to a depth of $1 \mathrm{~mm}$ short of working length, followed by respective irrigation with $6 \mathrm{ml}$ of the irrigants at a rate of approximately $2 \mathrm{ml} / 15$ seconds. Deep grooves were made on the buccal and palatal aspect of the root. Longitudinal sectioning was done by using chisel and mallet. Samples were examined under Scanning electron microscope. Scanning electron microscopy (Zeiss), which can assess the effectiveness of various irrigants in the removal of smear layer:

Smear layer removal scores (Rome et al.: 1985)

\begin{tabular}{|c|c|}
\hline Score & Interpretation \\
\hline $\mathbf{0}$ & No smear layer \\
\hline $\mathbf{1}$ & $\begin{array}{c}\text { Smear layer present only in } \\
\text { aperture of dentinal tubules }\end{array}$ \\
\hline $\mathbf{2}$ & $\begin{array}{c}\text { Thin smear layer covering the } \\
\text { root canal surfaces and } \\
\text { dentinal tubules openings }\end{array}$ \\
\hline 3 & $\begin{array}{c}\text { Heavy smear layer masking } \\
\text { dentinal tubule apertures }\end{array}$ \\
\hline
\end{tabular}

\section{STATISTICAL ANALYSIS}

The collected data were analyzed by one-way analysis of variance to compare the mean of the groups. The post- hoc test (Tukey) was performed to find the interrelationship between different groups of significant difference $\quad(\mathrm{p}<0.05$; confidence interval 95\%).

\section{RESULTS}

In qPCR, threshold cycle values were obtained. Threshold cycle values are inversely proportional to DNA population. In antimicrobial efficacy, the Mean value of $\mathrm{NaOcl}$ showed higher antimicrobial efficacy followed by Neem leaf extract and the lower antimicrobial efficacy was recorded with 
Tulsi extract. In the inter group comparison showed significant differences for all the three groups. Table 1 also depicts that Tulsi extract had the least antimicrobial efficacy among three irrigants.

Similarly, the mean smear layer removal by different irrigants at different root levels, $17 \%$ EDTA showed the maximum smear layer removal (1.20 ) followed by Neem leaf extract(1.9). Tulsi extract (2.7) showed the least smear layer removal. Hence Tulsi has poor smear layer removal efficacy and comparable antimicrobial efficacy when compared with Neem extract. The smear layer removal efficacy of the three groups are depicted in Table 2.

\section{DISCUSSION}

Elimination of microflora in the root canal is not achieved only by cleaning and shaping of the root canal. Because the areas which are inaccessible in the root canal by the cleaning and shaping lead to endodontic failure. Proper irrigation is essential to eliminate the microflora in the inaccessible areas in the root canal. Young tender branches of Neem are used as "chewing sticks" to keep the teeth and gum clean and healthy. Toothpaste containing neem is also available in India and Europe.Limited clinical trials have shown neem toothpaste have a potential to cure gingivitis.5,6 For over centuries, Tulsi termed as " The Queen of herbs, " and it has been known for its remarkable healing properties. ${ }^{7}$ Because of the easy availability and its Known medicinal values of Neem and Tulsi, these two herbs were chosen for this study.

In this study Maxillary central incisors were selected to have single straight canals. Enterococcus faecalis is a persistent organism and plays a vital role in root canal infections. It is commonly found in failed root canals. E. Faecalis is inoculated into the root canal for about three weeks Because the 3-week inoculation of E.Faecalis in the root canal reaches a depth of 200 $\mu \mathrm{m}$ to $400 \mu \mathrm{m}$ into the dentinal tubules. ${ }^{6}$ Hence E. faecalis was chosen for this study. ${ }^{8}$

In this study, Quantitative Real-time Polymerase chain reaction was used to evaluate the Antimicrobial activity of an irrigant. In qPCR, during each amplification round fluorescent dye was released by the amplified DNA to cycles which allows the products to be detected and analyzed and measured in real-time when the amplification is the first detected. ${ }^{9}$

Removal of smear layer is mandatory because it does not permit a hermetic seal between the Gutta-percha and the sealer. ${ }^{7}$ For evaluating smear layer removal Scanning electron microscope is one of the most commonly used technique and hence it was used in the present study. ${ }^{10}$

From this study, 2 herbal extracts used in this study are proven to be safe, containing active constituents that have an antimicrobial, antioxidant and anti-inflammatory activity. Because of these Antimicrobial, Antiinflammatory, and therapeutic effects, These two potential extracts would appear promisingly to replace the traditional root canal irrigant. In this study, Neem leaf extract showed Significant Antimicrobial activity and smear layer removal efficacy because of its active constituents such as Nimbin, nimbidin and nimbidol and tulsi showed comparable antimicrobial efficacy because of its active ingredients such as Eugenol, Ursolic acid, carvacrol and oleanolic acid. Eugenol (l-hydroxy2-methoxy-4-allylbenzene), the active constituent present in Ocimum sanctum L., has been found to be largely responsible for the therapeutic potentials of Tulsi.

\section{CONCLUSION}

From this study, these two herbal irrigants are proven to be safe and effective. It can be concluded that neem leaf extract has a significant antimicrobial efficacy against E. faecalis and significant smear layer removal efficacy compared to $17 \%$ EDTA.

\section{REFERENCES}

1. Vinothkumar TS, Rubin MI, Balaji L, Kandaswamy D. In vitro evaluation of five different herbal extracts as an antimicrobial endodontic irrigant using real time quantitative polymerase chain reaction. J Conserv Dent 2013;16(2):167-70.

2. Kandaswamy D, Venkateshbabu N. Root canal irrigants. J Conserv Dent 2010;13(4): 256 - 64.

3. Jain P, Rajan M. Role of herbal irrigants- A 
review. Journal of Pharm \& Biol Sci 2014;9(2):6-10. 4. Joshi B, Sah GP, Basneet BB, Bhatt MR, Sharma $\mathrm{D}$, Seubedi K, et al. Phyto chemical extraction and antimicrobial properties of different medical plants. Ocimum sanctum(Tulsi), Eugenia caryophyllata(clove) and Azhadiracta indica (Neem). Journal of Microbiology 2011;3(1): 1-7.

5. Hegde V. Enterococcus faecalis: clinical significance and treatment considerations. Endodotology 2009;21:2:48-54.

6. Gopalakrishnan S, Rajesh S, Ravi J. A comparative evaluation of antimicrobial efficacy of cinnamon and garlic as endodontic irrigants against enterococcus faecalis - An in vitro study. Endodontology 2014; 26(1):149-57.

7. Podar R, Kulkarni GP, Dadu SS, Singh S, Sing $\mathrm{SH}$. In vivo antimicrobial efficacy of $6 \%$ Morinda citrifolis, Azadirachta indica and 3\% sodium hypochlorite as root canal irrigants. European Journal of Dentistry 2015;9(4):529-34.

8. Babaji P, Jagtap K, Lau H, Bansal N,Thajuraj S, Sondh P. Comparative evaluation of antimicrobial effect of herbal root canal irrigants (Morinda citrifolia, Azadirachta indica, Aloe vera) with sodium hypochlorite: An in vitro study. J Int Soc Prev Community Dent 2016;6(3): 196-9.

9. Bodhar R. In vivo antimicrobial efficacy of $6 \%$ Morinda citrifolia, Azadirachta indica, and 3\% sodium hypochlorite as root canal irrigants. Eur J Den 2015; 9(4):529-34.

10. Chhabra N, Gyanani H. Smear layer removal efficacy of the combination of herbal extracts in two different ratios either alone or supplemented with sonic agitation: An in vitro scanning electron microscope study 2015; 18(5):374-8.

\section{$\underline{\text { AUTHOR AFFILIATIONS }}$}

Professor

PG Student

PG Student

Department Of Conservative Dentistry \& Endodontics, Rajas Dental College \& Hospital

\section{Corresponding Author:}

Dr. Sheerin Sarthaj

\section{PG Student}

Department Of Conservative Dentistry \& Endodontics

Rajas Dental College \& Hospital

Kavalkinaru, Tamil Nadu-627105

For manuscript enquiry/author contact details, e-mail at: maunscriptenquiry.ihrj@gmail.com 


\section{LEGENDS}

\begin{tabular}{|c|c|c|c|c|}
\hline IRRIGANTS & No. & MEAN & $\begin{array}{l}\text { INTERGROUP } \\
\text { COMPARISION }\end{array}$ & p-value \\
\hline $\mathrm{NaOcl}$ & 20 & 34.20 & $\begin{array}{c}\text { Neem leaf extract } \\
\text { Tulsi extract }\end{array}$ & $\begin{array}{l}0.513 \\
0.000\end{array}$ \\
\hline Neem & 20 & 33.93 & $\begin{array}{c}\text { Naocl } \\
\text { Tulsi extract }\end{array}$ & $\begin{array}{l}0.513 \\
0.000\end{array}$ \\
\hline Tulsi & 20 & 31.86 & $\begin{array}{c}\text { Naocl } \\
\text { Neem leaf extract }\end{array}$ & 0.000 \\
\hline
\end{tabular}

Table 1. Antimicrobial efficacy of the three groups

\begin{tabular}{|c|c|c|c|c|}
\hline IRRIGANTS & No. & MEAN & $\begin{array}{l}\text { INTERGROUP } \\
\text { COMPARISON }\end{array}$ & p-VALUE \\
\hline EDTA & 20 & 1.20 & $\begin{array}{c}\text { Neem leaf extract } \\
\text { Tulsi extract }\end{array}$ & $\begin{array}{l}0.074 \\
0.000\end{array}$ \\
\hline Neem leaf extract & 20 & 1.90 & $\begin{array}{c}\text { EDTA } \\
\text { Tulsi extract }\end{array}$ & $\begin{array}{l}0.074 \\
0.037\end{array}$ \\
\hline Tulsi extract & 20 & 2.70 & $\begin{array}{c}\text { EDTA } \\
\text { Neem leaf extract }\end{array}$ & $\begin{array}{l}0.000 \\
0.037\end{array}$ \\
\hline
\end{tabular}

Table 2. Smear layer removal efficacy of the three groups 